\title{
IMPACT STUDY OFGROUND WATER AND SOIL QUALITY IN AND AROUND MUNICIPAL SOLID WASTE DUMP-YARD IN CHIDAMBARAM TOWN
}

\author{
Pavithra $\mathbf{R}^{1}$, Venkataraman $\mathbf{T}^{2}$ \\ ${ }^{1}$ PG Student, Department of Civil Engineering, Annamalai University Chidambaram \\ ${ }^{2}$ Assistant Professor, Department of Civil Engineering, Annamalai University Chidambaram
}

\begin{abstract}
The management of municipal solid waste has become an acute problem due to enhanced economic activities and rapid urbanization. Increased attention has been given by the government in recent years to handle this problem in a safe and hygienic manner. The impacts due to the solid waste dumpsites are not confined merely to the disposal site. Clearly such sites possess a serious health risk not just in terms of degradation of groundwater quality also due to the related problems associated with littering, scavenging birds etc. Chidambaram dump yard chosen for this study is one such dumpsite which is located nearer to schools, residential area and national highway. It may constitute an environmental problem, if the leachate migrates into the ground water. Therefore, this study we design to determine the effects of the dumpsite on the surrounding residential area in and around the dumpsite. Soil and groundwater samples were collected nearer the dumpsite to study the possible impact of solid waste effect on ground water and soil quality of the physic-chemical parameters. It has been found that most of the parameters of water are not in the acceptable limit in accordance with the IS:10500-2001 drinking water quality standards. It is concluded that the contamination is due to the solid waste materials that are dumped in the area. The pollution of soil by lead was identified.
\end{abstract}

Keywords: Water Quality and Soil Quality, Solid Waste Dump Yard, Chidambaram. $* * *$

\section{INTRODUCTION}

Human activities create waste, and it is the way these wastes are handled, stored, collected and disposed of, which can pose risks to the environment and to public health. In urban areas, especially in the rapid urbanizing cities of the developing world, problems and issues of Solid Waste Management (SWM) are of immediate importance. Typically one to two thirds of the solid waste generated is not collected. Furthermore, even collected waste is often disposed of in uncontrolled dumpsites and/or burnt, polluting water resources and air. The large scale production and improper disposal of waste has become a source of pollution and further accumulation of garbage has resulted in serious deterioration in quality of life and the ecological balance.

\subsection{Water Exposure}

Landfills or Dumpsites have been identified as one of the major threats to groundwater resources. Waste placed in dumpsites or open dumps are subjected to either groundwater underflow or infiltration from precipitation. The dumped solid wastes gradually release its initial interstitial water and some of its decomposition by-products get into water moving through the waste deposit. Such liquid containing innumerable organic and inorganic compounds is called 'leachate'. This leachate accumulates at the bottom of the dumpsite and percolates through the soil.

\subsection{Soil Exposure}

The soil profile characteristics will be altered to a great extent due to the influence of MSW accumulating on the soil surface. Open dumpsites are used widely to dispose of municipal solid wastes. Problems that arise even with apparently properly constructed landfill include, leachate generation when the surface is permeable. The movement of water is first through dumps and then through soil results in soil pollution. In general, solid waste includes garbage, domestic refuse and discarded solid materials such as those from commercial, industrial and agricultural operations. They contain increasing amounts of paper, cardboards, plastics, glass, old construction material, packaging material and toxic or otherwise hazardous substances. These can in the long run, get deposited to the soils of the surrounding area and pollute them by altering their chemical and biological properties. From the analysis of soil samples near to landfill area showed that heavy metals such as lead $(\mathrm{Pb})$, copper $(\mathrm{Cu})$ and Iron $(\mathrm{Fe})$ are present in the soil and that these may also contaminate soil water which constitutes the major sources of drinking water. According toTesfaye (2007) the toxicity of lead could lead to encephalopathy, 
renal effect, and hematological effect. The World Health Organization (WHO) had confirmed the effects of lead intake to include, abortion, infant mortality, malformation of fetus, genetic mutilation, retarded growth, intoxication, depression of respiration and chromosomal aberrations.

\section{STUDY AREA}

Chidambaram town lies between $11023,38.95$ "N and 79041 '12.88'Eelevation $34 \mathrm{ft}$ and it has 64,000 population approximately and it produce solid waste $34 \mathrm{mt} /$ day. Chidambaram municipal solid waste dump-yard is situated near Ommakulam area and out of $3 \mathrm{~km}$ from chidambaram. Dumpsite has 4.5 acre it may constitute an environment problem,if the leachate migrates into the ground water. The presence of bore well at the landfill sites threatens to contaminate the ground water. People around the dump yard have reported that the dump yard has become nuisance for their living. This study also focuses the possible impact of solid waste effect on soil and ground water quality by the physico-chemical and biological parameters.



Figure 2.1 Satellite View of Solid Waste Dump yard and Chidambaram Town.



Figure: 2.2 Solid Waste Dump yard.
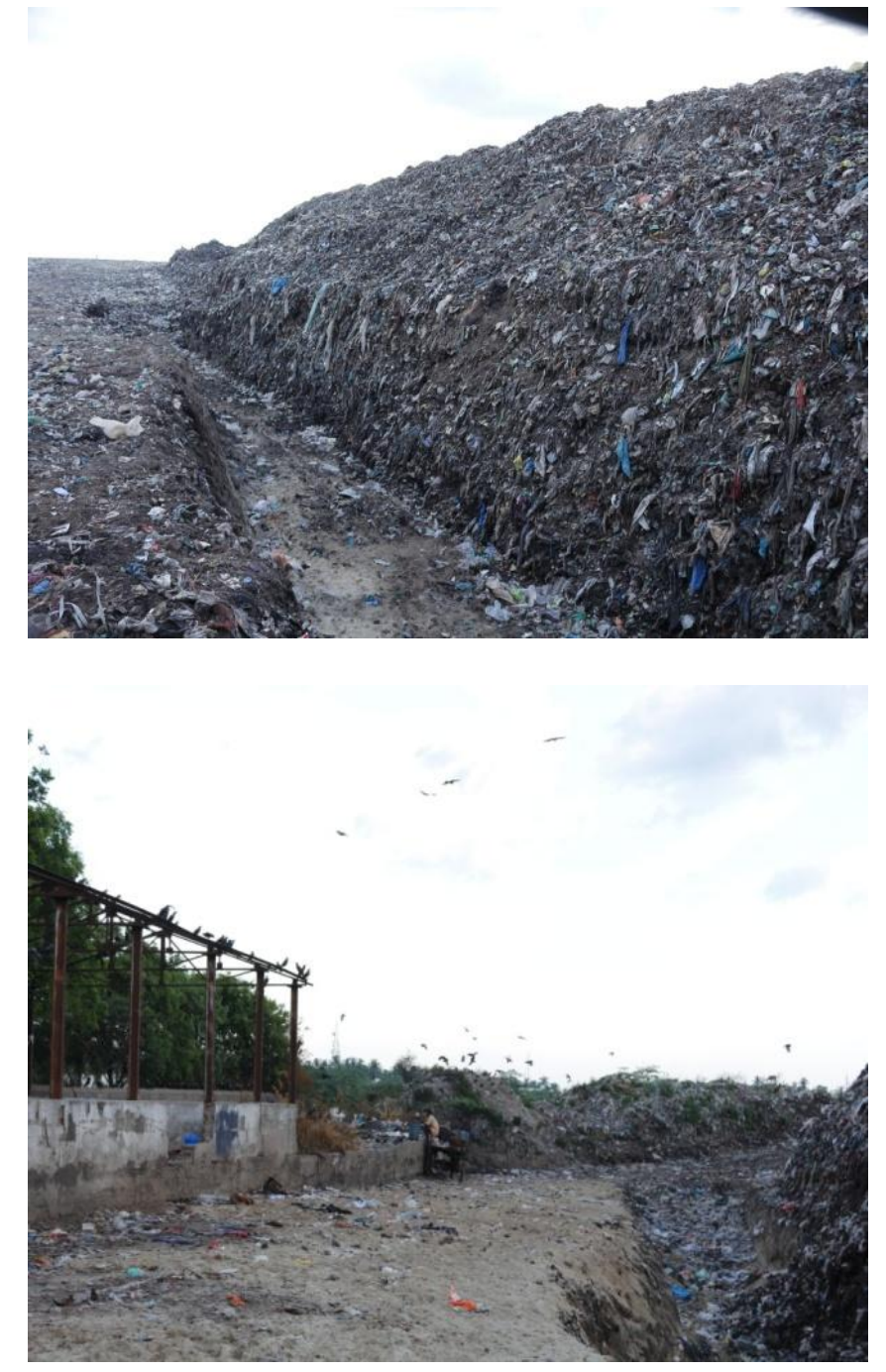

\section{METHODOLOGY}

\subsection{Sampling Size}

$500 \mathrm{~m}$ radius around the dumpsite was selected as study area. Sampling locations around the site was selected based on the groundwater flow direction. 9 soil and groundwater sampling locations were identified. W1, W2, W3, W4, W5, W6, W7, W8, W9 and W10 are groundwater sampling locations. S1, S2, S3, S4, S5 and S6 are soil sampling locations.Soil sampling were done based on USEPA random sampling technique where in soil samples were taken at three depths $(0-30,30-60,60-90 \mathrm{~cm})$ from each location using a sharp spade. Soils collected from these layers were placed separately in a glass jar and then were analysed. Source for groundwater were well water and bore water. Locations 1,2,3,4,5,6,7,8 and 9 are bore water at the depth of $20 \mathrm{ft} .10^{\text {th }}$ sample is from pond water which is situated near dumpyard and also near to burial ground. Water samples have been analyzed for selected relevant physico-chemical parameters and heavy metals.Analysis was carried out according to given in standard methods (APHA, 1994).Various physico-chemical and biological parameters such as $\mathrm{pH}$, total hardness, calcium, magnesium, sodium, 
potassium, chlorides, alkalinity, fluoride, sulphate, nitrate ,nitrite, phosphate, cadmium, chromium, lead, nickel, Zinc, faecal coliform and total coliform were examined in groundwater samples.

\subsection{Waste Characterization}

The composition of the wastes at dumpsite includes both degradable (garbage or food waste and paper waste) and non-bio degradable (plastics, hazardous waste, and other metal containing substance). The composition of solid waste includes papers and cartons, food remnants, glass and bottles, plastic and polythene, metals and tins, textiles, rags and other minerals. On average municipal solid waste from the dumpsite consisted of $65.6 \%$ volatile solids, $14.5 \%$ fixed dumps, $18.1 \%$ liquid and $1.8 \%$ other compounds. The average bio degradability fractiom is 0.807 , carbon to nitrogen ratio of 27:1. The percentage composition of wastes consisted of organic biodegradable wastes $35.6 \%$, glass $24.5 \%$, metals $10.8 \%$, textiles $6.9 \%$, wood $7.6 \%$, sludge $5.6 \%$.

\subsection{Identification of Sampling Locations}

$500 \mathrm{~m}$ radius around the dumpsite was selected for the ground water and soil sampling. Based on the groundwater flow direction 9 ground water locations were identified from this area for analysis. 27 water samples were collected from the identified sampling locations. From each location three water samples were collected for analysis on weekly basis. Source for water samples were wells and hand pumps. Table 3.1 shows the collected water samples location data. Water samples collected from indentified sampling locations were analysed to see the level of groundwater contamination. Samples were analysed for drinking water parameters.

Table 3.1 Water Samples Location Data

\begin{tabular}{|l|l|l|l|l|l|}
\hline s.no & $\begin{array}{l}\text { sampling } \\
\text { locaion }\end{array}$ & types of sample & place of collected sample & $\begin{array}{l}\text { distance from } \\
\text { the site }(\mathrm{m})\end{array}$ & depth $(\mathrm{ft})$ \\
\hline 1 & w1 & bore water & Within dumpsite location & 50 & 24 \\
\hline 2 & w2 & bore water & Hand pump on road side & 100 & 24 \\
\hline 3 & w3 & bore water & Hand pump on household & 170 & 24 \\
\hline 4 & w4 & bore water & Hand pump in petrol bunk & 250 & 24 \\
\hline 5 & w5 & bore water & Hand pump near residential area & 300 & 24 \\
\hline 6 & w6 & bore water & Hand pump in household & 370 & 24 \\
\hline 7 & w7 & bore water & Hand pump in school & 450 & 24 \\
\hline 8 & w8 & bore water & Hand pump in household & 500 & 24 \\
\hline 9 & w9 & bore water & Hand pump in primary school & 550 & 24 \\
\hline 10 & w10 & pond water & Well water & 170 & 3 \\
\hline
\end{tabular}

Similarly six soil sampling locations were identified within the distance of $500 \mathrm{~m}$ radius around the dumpsite. Soil samples were taken at three depths $(0-30,30-60,60-90 \mathrm{~cm})$ from each of sixlocations using a sharp spade. Soils collected from these layers were placed separately in a glass jar and then were analysed. Location and distance of these soil sampling points from the dumpsite is given in the table 3.2

Table 3.2 Soil Samples Location Data

\begin{tabular}{|l|l|l|l|}
\hline $\begin{array}{l}\text { S.n } \\
\text { o }\end{array}$ & $\begin{array}{l}\text { sampli } \\
\text { locati } \\
\text { on }\end{array}$ & place of collected sample & $\begin{array}{l}\text { dista } \\
\text { nce } \\
\text { from } \\
\text { the } \\
\text { site } \\
(\mathrm{m})\end{array}$ \\
\hline 1 & S1 & within dump yard & 0 \\
\hline 2 & S2 & outer area of dump yard & 0.2 \\
\hline 3 & S3 & bye-pass nearer to dump yard & 150 \\
\hline 4 & S4 & household near to dump yard & 200 \\
\hline 5 & S5 & burial ground near to dump yard & 300 \\
\hline 6 & S6 & $\begin{array}{l}\text { residential and hospital area near } \\
\text { to dumpyard }\end{array}$ & 450 \\
\hline
\end{tabular}

Collected groundwater samples were analyzed for physicochemical parameters and heavy metals, which cause health problems when exceeds the acceptable limit. Table 4.3 shows the characteristics of groundwater in the study area. Analytical results of physicochemical characteristics of groundwater samples are presented above which indicate that the dumpsite is the point source for all the contaminants identified because groundwater flow is outward away from the dumpsite, and the concentration of pollutants decreases radically as we move away from the landfill along the groundwater flow.

\section{RESULTS AND DISCUSSION}

\subsection{Effect of Distance on Pollutant Concentration}

$\mathrm{pH}$, electric conductivity, and turbidity of the samples are in tolerable limit. It ranges from $6.00-7.00 \mathrm{pH}$ it shows its slightly acdic in nature.0.43-2.9 specific conductance range its in tolerable limit because water samples are slightly in acidic nature not by salty nature. 2.1-7.2NTU some of water samples are only contains moderate turbidity so that the permissible limit is tolerate ground water near the dumpyard. 
Hardness of the sample are analysed by the method complex matrix method hardness is called by the presence of multivalent metallic cation and is largely due to $\mathrm{cl}$ and $\mathrm{mg}$ ion. From my study sampling are in dumpsite and downstream of the dumpyard is in above the tolerant level but upstream side of dumpyard is slightly low and much lower than permissible limit

Concentration of lead at the dumpsite was found to be 0.5 $\mathrm{mg} / \mathrm{l}$ which is 5 times higher than the permissible limit of $0.05 \mathrm{mg} / \mathrm{l}$. In upstream direction, i.e towards north- west of dumpsite concentration of lead is within the standard limit whereas at a distance of $500 \mathrm{~m}$ in south east direction lead has concentration of $0.07 \mathrm{mg} / \mathrm{l}$ and at the distance of 300 mits around $0.1 \mathrm{mg} / \mathrm{l}$. This shows concentration of pollutants decreases radically.

Calcium showed high concentrations level in all samples in downward direction. The highest concentration of $\mathrm{Ca}$ was measured at the site with the value of $310 \mathrm{mg} / 1$, whereas the lowest $\mathrm{Ca}$ concentration was measured at the distance of $450 \mathrm{~m}$ away in north-west direction which is at upstream with the value of $124.5 \mathrm{mg} / \mathrm{l}$. In the south east direction lowest concentration was recorded at the distance $300 \mathrm{~m}$, which was found to be $147.4 \mathrm{mg} / \mathrm{l}$. Concentration of Ca are not within the standard levels for drinking in downward direction.

The concentration of nitrate in water samples are within the range of 10-75 $\mathrm{mg} / \mathrm{l}$ respectively. At the dumpsite, maximum concentration of nitrate and nitrite were recorded which were found to be 75 and $15 \mathrm{mg} / \mathrm{l}$. But in the northwest, at the farthest distance of $300 \mathrm{~m}$ from the dumpsite it was found to be $65 \mathrm{mg} / \mathrm{l}$ of nitrate. Tesfaye Z. (2007), have reported that natural concentration of nitrates in ground water are very low, since plants take up of the nitrogen near the ground surface before it can reach the water table. However, levels of nitrates in nearby well recorded at the dumping site are relatively high. This might be explained by the fact that the land is contaminated by leachate. Nitrates are a concern because it does not break down quickly in the soil and does not stick to soil particles. Instead, it travels rapidly with the groundwater and can seep a long way from its source.

All other parameters analysed like cadmium, zinc, nickel, chromium, sulphate, alkalinity, chloride potassium, sodium, magnesium were within the limit. Therefore, only calcium, phosphate, nitrite, nitrate, fluoride and lead were identified as the potential chemical of concern in water pathway due to dumpsite.

\subsection{Chemical Analysis of Soil Extracts}

The soil samples were analysed for the concentration of lead, Nickel, Manganese, Magnesium, iron, Copper and Zinc, chromium and cadmium and their results are given the table 4.1From the below table it was observed that the concentrations of metals in the downstream direction of dump sites and upstream direction indicates there is an evidence of relative increase in the concentration of heavy metals and basic ions, available in soils near to dump sites compared to those in soils away from the dump sites.

Table 4.1 soil quality concentrations of metals in downstream. (all parameters in $\mathrm{mg} / \mathrm{l}$ except $\mathrm{pH}$ )

\begin{tabular}{|l|l|l|l|l|l|l|}
\hline $\begin{array}{l}\text { Parametey } \\
\text { Sanple }\end{array}$ & 1 & 2 & 3 & 4 & 5 & 6 \\
\hline no & 7.91 & 7.73 & 7.74 & 7.65 & 7.58 & 7.64 \\
\hline Lead & 0.78 & 0.07 & 0.14 & 0.3 & 0.28 & 0.52 \\
\hline Zinc & 2.25 & 1.9 & 0.69 & 0.89 & 0.49 & 0.79 \\
\hline Cadmium & 0.04 & 0.02 & 0.01 & 0.01 & 0 & 0 \\
\hline Sodium & 160.12 & 106.55 & 17.33 & 15.47 & 115.74 & 33.31 \\
\hline Nickel & 2.69 & 1.36 & 0.5 & 0 & 0.27 & 0 \\
\hline Calcium & 9.2 & 4.9 & 4.95 & 4.53 & 4.71 & 15.7 \\
\hline Copper & 3.8 & 2.07 & 1.67 & 0.81 & 0.74 & 3.98 \\
\hline
\end{tabular}

The metals considered in the study include that which is micro-nutrients such as copper manganese, iron and zinc and the non-toxic heavy metals which are toxic to plants when present in the soil at concentration above tolerance level. This latter class of heavy metals includes lead, nickel, chromium, and cadmium. Others are exchangeable metallic cations and non-metal like magnesium.

Based on the results obtained, there was a significant difference between the concentration of most metals in the upstream and downstream direction from the dumpsite in almost all samples.

In the downstream direction the concentration of copper ranged between 43-62 mg/l and at upstream concentration ranged between $10-37 \mathrm{mg} / \mathrm{l}$. this show the concentration of copper (CU) in soil at the dump-yard was higher than the permissible limit. This might be due to the indeterminate disposal of copper containing wastes at the dumpsite. There was a significant different between the concentration of copper in soils at the upstream and downstream. From the results obtained, the average concentration of copper in soils at the dump site was highest at the site while, at the distance of $350 \mathrm{~m}$ in north-west, which is farthest from the site in the upstream direction was the lowest in copper concentration. It has been reported by (Dara 2003) that a biodegradable waste introduces metallic cu into soil at a level slightly above the natural level for soil. This might be responsible for the high concentration of cu in soils at the dump-yard. This shows that the waste materials at the dumpsite might have contributed to the increase in the concentration of copper above background concentration. 
The concentration of lead in soil samples analyzed ranged from $10-51 \mathrm{mg} / \mathrm{l}$.The highest concentration of lead was obtained in soils at the dump site while the lowest concentration was found in the upstream direction of the dumpsite, which is at the upstream direction. Level of lead in the upstream samples ranged from $10-32 \mathrm{mg} / \mathrm{l}$. This is below the natural level for soil which implies that the decomposing of wastes at the dumpsite mighthave introduced lead into soils. The major source of lead pollution is industrial source (Dara 2003). The pollution of soil by lead is a very serious problem this is due to the fact that lead is cumulative pollutant (Dara 2003) and the continues disposal of lead containing waste into the environment should be discouraged. There was a significant difference between the concentration of lead in soils nearer to site as compared to control samples and this shows that the wastes at the dumpsite contain significant amount of lead.

The concentration of nickel in soil samples analysed ranged from 0.1 to $84 \mathrm{mg} / \mathrm{l}$. High concentrations of nickel were obtained in soils at dumpsites, while low values were recorded at the distance of $350 \mathrm{~m}$ in north-west which is the farthest point from the dumpsite in upstream. In the northwest directions, the concentration of nickel in soils ranged from 0.1 to $17 \mathrm{mg} / \mathrm{l}$. These values were found to be below the natural range of concentration for nickel in soils. The difference in the concentration of nickel in the control samples and downstream samples suggests that nickel might have been introduced by biodegradation of nickel containing wastes into the environment. There was a significant difference between themthis reveal that the uncontrolled disposal of solid waste and hazardous waste into the environment can significantly increase the background concentration of nickle in the environment.

The concentration of zinc, cadmium and copper in soil samples analysed ranged from $0.49-2.25 \mathrm{mg} / 1,0.1-24 \mathrm{mg} / \mathrm{l}$, 0-0.04 mg/l and 0.74-3.98 mg/l respectively. These values were found to be below the natural range of concentration for nickel in soils. Both in the downstream and upstream direction concentration of these metals were within the limit.

From these analysis magnesium, iron, nickel, lead and copper were identified as potential chemical of concern in soil media due to the presence of dumpsite.

\subsection{Effect of Depth on Pollutant Concentration}

Iron and Magnesium concentrations in samples indicated an increase of these metals in 0-30, 30-60 cm and 60-90 cm depths in all soil samples. As the depth increases their concentration were increasing. The lead, nickel and copper concentrations were increasing as the depth was increasing. But control samples showed slight fluctuation in the concentration of lead with respect to depth, as the concentration of lead was very less at the $60-90 \mathrm{~cm}$ depth compared to top layer.

\section{CONCLUSION}

The study discovered that the concentration of wastematerials in the landfill site had systematically polluted thesoil and groundwater over time. The effect of such pollutionas determined from the study declined away from thepolluting source.All parameters analysed like cadmium, zinc, nickel, chromium, sulphate, alkalinity, chloride potassium, sodium, magnesium were within the limit. Therefore, only calcium, phosphate, nitrite, nitrate, fluoride and lead were identified as the potential chemical of concern in water pathway due to dumpsite.

The concentration of zinc, chromium, cadmium and manganese in soil samples analysed ranged from 22-142 $\mathrm{mg} / \mathrm{l}, \quad 0.1-24 \mathrm{mg} / \mathrm{l}, \quad 0.01-0.9 \mathrm{mg} / \mathrm{l}$ and $10-316 \mathrm{mg} / \mathrm{l}$ respectively. These values were found to be below the natural range of concentration for nickel in soils. Both in the downstream and upstream direction concentration of these metals were within the limit.From these analysis magnesium, iron, nickel, lead and copper were identified as potential chemical of concern in soil media due to the presence of dumpsite.The lead, nickel and copper concentrations were increasing as the depth was increasing. But control samples showed slight fluctuation in the concentration of lead with respect to depth, as the concentration of lead was very less at the 60-90 cm depth compared to top layer.

\section{REFERENCE}

[1]. Tesfaye Z. (2007), 'Groundwater Pollution And Public Health Risk Analysis In The Vicinity Of Reppi Solid Waste Dumping Site',Wat.Sci.Tech., Vol. 25, No.10. pp. $203-209$.

[2]. Aluko O., Sridhar M.K. and Oluwande P. (2003), 'Characterization of leachate from a municipal solid waste landfill site in Abadan', J. Environmental Health Research, Vol 2, pp. 32-37.

[3]. Padmavathi M. (2008), 'Assessment of Ground Contamination at Perungudi Municipal Dumping Yard in Chennai'.

[4]. N Raman and D Sathiyanarayanan (2008), 'Impact of Solid Waste Effect on Ground Water and Soil Quality nearer to Pallavaram Solid Waste Landfill Site In chennai', Vol 1, No.4 (2008), 828-836.

[5]. Dara, S. S. (1993), Atextbook of environmental chemistry and pollution control, S. Chand \& Company Ltd, New Delhi. 